Published on Reviews in History (https://reviews.history.ac.uk)

\title{
The History of Emotions: An Introduction
}

Review Number: 1752

Publish date: Thursday, 16 April, 2015

Author: Jan Plamper

ISBN: 9780199668335

Date of Publication: 2015

Price: $£ 35.00$

Pages: 368pp.

Publisher: Oxford University Press

Publisher url: http://ukcatalogue.oup.com/product/9780199668335.do

Place of Publication: Oxford

Reviewer: Rob Boddice

The history of emotions, a rocket taking off according to Jan Plamper, seems to be screaming 'know thyself!' at psychology in all its various forms, but most specifically at neuroscience. The development of a hard science of emotions has involved, with every step 'forward', the forgetting of the previous step.

Emotions are always what they are now, and whatever the natural sciences thought they were last week is no longer relevant. But, and this is the slowly falling hammer blow of Plamper's book, changes in the status of what emotions are must have some diachronic effect on what emotions mean, how they are experienced, and what things are done in their name.

Plamper's book is dominated by two, apparently incommensurate, historical narratives that encompass parallel histories of the study of emotions. Plamper clears the way for others to approach the history of emotions by mapping the multidisciplinary intellectual architecture that has supplied us with a nature/culture dualism in contemporary understandings of what emotions are and where they come from. Though it is his intention to reveal 'the study of emotion beyond the dichotomy of universalism and social constructivism', it is clear that he is much more sympathetic to the anthropological relativists than to the universalism of the life sciences. Yes, Plamper rejects the most radical wing of post-modern social construction, but a huge space for the influence of culture is carved out here, and his assault on the recent history and rise to prominence of the life sciences is a sustained piece of intellectual belligerence. The bete noire of the piece is Paul Ekman, who stalks Plamper's pages long before his formal introduction in chapter three. As the chief purveyor of the idea that emotions and their expressions are universal, Ekman is stood accused of arrogating a position in the study of the emotions that flies in the face of a raft of serious criticism. This is where Plamper is at his best, cutting a swathe through disciplines where other historians might fear to tread.

The two chapters covering the history of this dualism take up well over half of the book. Immediately following is a discussion, long awaited, of what historians of emotion have made of it all. William Reddy dominates here, although he does not escape unscathed. Elsewhere I've called the history of emotions a 'loose canon', since its beginnings seem to have been dominated by a flood of competing ideas and jargon that are reconciled only with difficulty.(1) Plamper lays it all out (although not all in one place), from emotional communities (Rosenwein), to emotional regimes, refuges, suffering and liberty (Reddy), to emotional practices (Scheer), emotionology (Stearns and Stearns) and most importantly 'emotives' (Reddy). 
Reddy lurks in Plamper's book in the shadows, with Ekman and his ilk in his sights, until finally emerging as the most important historian of emotions the field has yet known. Plamper provides the entry point for any scholar looking for a succinct analysis of Reddy's formative achievements and their impact.(2) Reddy is up there to be criticised. There are limits, as Plamper points out, to Reddy's theories. His attempt to create a position from which political evaluation can be reintroduced, against the radical consequences of poststructuralism and the flattening effect of biological universalism, is critiqued as being potentially circular; his 'emotives' are exposed as being limited to speech acts at the expense of practices more broadly conceived. But these criticisms come in the form of acknowledgement, that Reddy did more than anyone else to fuel the history-of-emotions rocket. Indeed, it might be time for historians of emotions to start to work with its best theorist (his concept of 'utterances' could easily be expended to include non-verbal forms of expression and bodily practice, for example, reinvigorating 'emotives'), instead of pursuing an endless cycle of wheel re-invention and jargon proliferation. Plamper's 'introduction' to the history of emotions might cause the neophyte to shake her head at the unresolved and growing plurality of theoretical approaches.

Plamper does not push a strong agenda of his own, save for his introduction, which I would strongly recommend newcomers to the field to skip and read last. It is a much stronger statement of intent than the conclusion proper, and gains its energy and polemical spirit from the tone of the book as a whole. There are elements of it that, without an understanding of the overarching narrative, might strike the reader as out of place. In particular, it contains Plamper's most assertive statement concerning his rejection of the most extreme form of social constructivism. The form this takes raises an historiographical eyebrow. Plamper forcefully insists on the meta-category of 'emotion' (an assertion that is confused in the English translation with the word 'feeling', which made much more sense in the original German). Historians wary of anachronism will doubtless be concerned at the circumspection concerning the study of emotions in the past in the terms employed by historical actors themselves. In striving to find a way to thread the needle of balance between the two sides of the debate, Plamper is looking for a place to stand, and for this, he insists, historians need a working definition of emotions and a meta-category - emotion - with which we can all work. I am not convinced, and indeed, I think that this is representative of the principal tension in Plamper's book. Do historians need to know - at all - what emotions actually are? In striving to stay up to date with whatever it is emotion scientists are telling us, and insisting that they also listen to us, there is a risk that we forget our purpose: conducting research on what emotions mean (have meant). Historical definitions of sense and sensibility, feeling and affect, ????? and passio, carry a cultural weight that affects how historical actors have acted and interacted, formed communities or boundaries of exclusion, and constructed institutions, both social and intellectual. I can no more talk of the 'emotions' in Spinoza than I can equate the sympathy in Adam Smith's Theory of Moral Sentiments to the 20th-century neologism 'empathy', or indeed, to a contemporary understanding of sympathy.

I do not see, as Plamper does, the radical pole of social construction in this. On the contrary, it appeals to the basic tenets of historical empiricism. If the goal is to see how 'emotions' not only have a history, but make history, then 'emotion' is only a short-hand label that gives way to the language of the past as we find and reconstruct it. Where the word 'emotion' itself enters into the historical frame, the historian is behooved to lay out its own complex semantic, intellectual and experiential history, which indeed Plamper does throughout this book in such exemplary fashion. The search for a meta-category seems no nearer for Plamper's efforts, which seem instead to point to the sand-in-hand problem of meta-categories. The more we clutch at them, the more they slip through our fingers.

Plamper's own suggestions for the vast potential of the history of emotions seem, in fact, to point in this direction. It should be noted that the English text here hasn't been updated from the German edition of 2012, meaning the history-of-emotions rocket ship is flying at a significantly higher altitude than indicated. Plamper's suggested research programmes - political history, social history and emotions; economic history and emotions; legal history and emotions; media history and emotions - are all substantially up and running, not least at the Centre for the History of Emotions in Berlin that was so formative in the production of Plamper's own text. There are myriad other potentialities, beyond the predominantly modern and Western 
focus of Plamper's book. But Plamper himself is well aware of this: the one significant - and enormously valuable - update from the German text is the extensive bibliography (in addition to a full glossary that clearly explains all the multidisciplinary jargon). While the text depends on works published until late 2011, with the exception of a few works, including Monique Scheer's influential piece on emotions as a kind of practice, the bibliography is inclusive of works in English up to 2014 and has been re-organised thematically. (3) The sheer volume of literature here is telling evidence of the speed at which the rocket is travelling (a cursory count shows 78 entries for 2012-14). If this were expanded to include French and German works in the history of emotions from the same period, that number might easily be doubled.

I suspect Plamper will not appreciate the connection, but I was struck while reading his book that its intellectual ancestor might be found in the early annals of the discipline of psychology itself. Just as Plamper unapologetically adopts the meta-category of 'emotion' to talk about a whole range of experiences that might fall under this head, but without forgetting those varieties, so Alexander Bain announced in The Emotions and the Will in 1859 that from now on 'emotion' would be the master label for a gamut of 'feelings, states of feeling, pleasures, pains, passions, sentiments, affections'. Furthermore, Bain sketched the beginnings of psychology bioculturally, juggling the 'natural' and the 'conventional' in a strikingly similar fashion to Plamper's attempts to represent and reconcile the 'universal' with the 'socially constructed'. According to Bain, it was 'in the power of education to change the natural and primitive course of the emotional currents'. Emotional outbursts were 'modified by ... conventions'. A 'new expression is substituted for instinctive utterances'. Significantly, he went so far as to say that such changes 'have no slight influence in changing the character of consciousness', determining 'the nature of the resulting mental condition'.(4) Doubtless thereafter there are major divergences, but this passage reads as wonderfully up to date and sympathetic to Plamper's purpose. It also serves to illustrate Plamper's point. Just as poststructuralism threw out the body with the bath water, the life sciences have forgotten from where they came.

\section{Notes}

1. Rob Boddice, 'The affective turn: historicising the emotions', Psychology and History: Interdisciplinary Explorations, eds. Cristian Tileag? and Jovan Byford (Cambridge, 2014), pp. 148, 163. Back to (1)

2. William Reddy, 'Against constructionism: the historical ethnography of emotions', Current Anthropology, 38 (1997), 327-51; The Navigation of Feeling: A Framework for the History of Emotions (Cambridge, 2001).Back to (2)

3. Monique Scheer, 'Are emotions a kind of practice (and is that what makes them have a history)? A Bourdieuian approach to understanding emotion', History and Theory, 51 (2012), 193-220.Back to (3) $<$

4. Alexander Bain, Emotions and the Will (London, 1859), pp. 3, 14-15, see also 61. Back to (4)

Source URL:https://reviews.history.ac.uk/review/1752

\section{Links}

[1] https://reviews.history.ac.uk/item/132445 